ORIGINAL ARTICLE

\title{
EVALUATION OF PATENT DUCTUS ARTERIOSUS BY USING TWO DIMENSIONAL ECHOCARDIOGRAPHY IN INFANT AND NEONATE
}

\author{
Azza Ali Khalil ${ }^{1}$, Amal Mohamed Abdellatif ${ }^{1}$, Shimaa Mohamed Elhady Kamal ${ }^{2} *$ \\ ${ }^{1}$ Pediatric Department Faculty of Medicine Zagazig University \\ ${ }^{2}$ Pediatric Department Abuhammad General Hospital Sharkia, Eygpt
}

Corresponding author :

Shimaa Mohamed Elhady

Kamal

Pediatric Department

Abuhammad General Hospital

Sharkia, Eygpt .

email:

shimaaelhady87@gmail.com

$\begin{array}{ll}\text { Submit Date } & \text { 2019-03-19 } \\ \text { Revise Date } & 2019-05-08 \\ \text { Accept Date } & 2019-05-11\end{array}$

\section{ABSTRACT}

Background: Patent ductus arteriosus (PDA) is a part of the typical morbidity profile of the preterm infant, with a high incidence of 80 $90 \%$ in extremely low birth weight infants born before 26 weeks of gestation. Whereas spontaneous closure of the ductus arteriosus (DA) is likely in term infants, it is less so in preterm ones. The aim of this study is to Evaluate Patent Ductus Arteriosus by using two dimensional echocardiography in infant and neonate. Method: The present study is a case-control study including 46 cases aged between neonate below 37 weeks of gestation to infant $<6$ months. This study was conducted in Neonatal ICU, Cardiology Unit and Pediatric Echocardiography Unit in Pediatric Department, Zagazig University. The period of the study was from January 2017 t0 December 2017. Results ECHO findings of both PDA cases and their controls were close to each other and there was no statistical significant difference between them except in size of left atrium which was significantly higher among PDA cases ranged from $0.91 \mathrm{~cm}$ to $1.7 \mathrm{~cm}$ with mean of $1.25 \pm 0.24$, also ratio of LVED\ AO was higher among PDA cases than their controls and the difference was statistically highly significant. 9 cases (39\%) of the studied PDA cases presented with high significant PDA, while 14 cases (61\%) had low significant PDA. Concolusion: 1. Clinical assessment is somewhat helpful at detecting PDA early in the course of sick infants. Echocardiography is a safe method of detecting PDA and classifying it as HSPDA and LSPDA .

Keywords: preterm infant; patent ductus arteriosus; functional echocardiography; ductus arteriosus.

\section{INTRODUCTION}

$\mathbf{P}$ DA is a common problem in neonates and an important contributor to morbidity especially in premature infant. It means abnormal persistence of an open lumen in the ductus arteriosus between the aorta and the pulmonary artery after birth. The ductus arteriosus is open during prenatal life, allowing most of the blood of the fetus to by pass the lungs, but normally this channel closes shortly after birth and change to fibrous cord called ligament arteriosus [1].
When it remain open. It places special burden on the left ventricule, since much of the ventricular output is being shunted from the aorta to the pulmonary artery .

The condition may coexist with other congenital malformation. So determination of its hemodynamic significance can be challenging [2].

Neonatologists often look to echochardiogram to clues that a heamodynamically significant patent ductus arteriosus (HSPDA) is present, 
coring enough flow to be athreat to a premature infant they are treating [2]

Reliable echochardiographic measures for HSPDA have, however, been elusive, because most markers don't attempt to determine true atrial size using volumes as normalized to patient size [1]

The principle that the distensible atrium will enlarge to accommodate the excessive pulmonary venous flow associated with important PDA more than the less distensible aorta, an LA: AO in excess of 1.5 is said to correlate with significant PDA shunt [2].

The likelihood of spontaneous closure of the ductus arteriosus (DA) in full-term infants without congenital heart disease is very high; in the preterm infant, closure rates are poorer [46].

According to the international literature, PDA is associated with not only increased mortality but also various neonatal comorbidities $[3,4,6$ 7]. These include cardiac failure, need for respiratory support, need for supplemental oxygen, bronchopulmonary dysplasia, pulmonary hemorrhage, intraventricular hemorrhage, abnormal cerebral perfusion, and necrotizing enterocolitis [4].

As clinical signs of PDA are not sensitive or specific enough, all extremely preterm infants at risk of developing PDA should undergo echocardiography. The main goal of the present review is to define and develop the different steps inevaluation of PDA by two dimention echochardiography

\section{METHODS}

The present study is a case-control study including 46 cases aged between neonate below 37 weeks of gestation to infant $<6$ months. this study was conducted in Neonatal ICU, Cardiology Unit and Pediatric Echocardiography Unit in Pediatric Department, Zagazig University. The period of the study was from January 2017 t0 December 2017.

\section{Groups;}

Cases 23 with PDA ,12 male /11 female and the age (days) was (54.9 \pm 39.5$)$. Control 23 healthy neonates, 11 male /12 female and the age (days) was $(62.7 \pm 57.5)$.

\section{Inclusion}

1-Age group from preterm neonate from one day to infant under 6 months.

2-congenital heart disease specially isolated PDA cases also PDA cases with patent foramen ovale.

\section{Exclusion criteria}

Patients more than 6 months old.

All patients with acute or chronic illness other than PDA.

Any Other congenital heart disease except patent foramen ovale.

\section{Methods:}

A written informed consent was obtained from all participants and the study was approved by the Research Ethical Committee of Faculty of medicine, Zagazig university. The work has been carried out in accordance with The Code of Ethics of the World Medical Association (Declaration of Helsinki) for studies involving humans.

\section{Full history talking}

Personal history: name, age, sex, order of birth, residence, maturity and These data taking from parents.

Present history: duration of illness

rate and difficulty in suckling or not. Anthropometric measurement: height, weight and body mass index

Family history: consanguinity, drug intake from baby and mother, mother disease

\section{Examination}

General examination: Appearance (pallor, cyanosis, jaundice, toxic face), wasting and vital signs (HR, RR, pulse).

Cardiac examination: Inspection (Precordial bulge, pulsations, scars, sinuses, dilated veins), palpation (thrill, pulsations), percussion, auscultation of heart sounds (murmurs, adventitious sounds)

\section{Chest examination}

Movement, shape (bulge, retraction), position of trachea (central or shift), tenderness, percussion space by space and in comparison, to other side. Auscultation of chest areas (breath sounds, air entry, vocal resonance and adventitious sounds). 
Two-dimensional echocardiography

Echocardiographic exams were performed with all subjects positioned in supine decubitus and left lateral decubitus with sedation if required using oral chloral hydrate.

Echocardiographic exams were performed by two dimensions the same operator using a Vivid (general electric) machine equipped with amulti-frequency matrix $\mathrm{M} 3 \mathrm{~S}$ and a7s transducers and simultaneous ECG recording at the Echocardiography Unit of Children's Hospital Zagazig University.

Initially, routine diagnostic imaging was performed, including color flow mapping, pulsed, and continuous wave Doppler. Color Doppler myocardial imaging was performed with a standard apical four- chamber view.

Sector size and depth were chosen to achieve a frame rate of $130 \pm 20$. Gain settings, filters and pulse repetition frequency were adjusted to optimize color saturation and continuous 1channel electrocardiographic monitoring was used throughout the study.

Three consecutive cardiac cycles were recorded during normal quiet respiration. Data were stored and the studies were video recorded for subsequent analysis.

Following parameters were evaluated;

\section{Cardiac dimension}

Aortic (Ao) and Left Atrium(LA) dimensions were measured from the parasternal short axis view

view

PDA was visualized from suprasternal

The main pulmonary artery, right and left branches were measured from the parasternal short axis view with tilting the plane of ultrasonic waves toward the base of the heart with slight cranial and leftward angulation of transducer

Interventricular septum diameter (IVS), posterior wall thickness (PW), left ventricular end-systolic (LVES), left ventricular enddiastolic (LVED) dimensions were measured from parasternal short axis view with orientation of the plane of sound just below the tip of mitral valve.
Conventional left ventricular systolic functions

The LVED and LVES dimensions parameters were measured from M-mode (MM) images. The EF and FS\% were calculated

$\mathrm{FS}(\%)=($ LVEDd-LVESd $) /$ LVEDd $\times 100$

Where LVEDd is left ventricular enddiastolic dimension, LVESd is left ventricular end-systolic dimension.

$\mathrm{EF}(\%)=(\mathrm{LVEDv}-\mathrm{LVESv}) / \mathrm{LVEDv} \times 100$

LVEDv left ventricular end-diastolic volume, LVESd is left ventricular endsystolic volume

Diastolic functions of left ventricle: by assessment of

-Mitral A velocity $(\mathrm{cm} / \mathrm{sec})$ : peak velocity during early diastole

-Mitral E velocity $(\mathrm{cm} / \mathrm{sec})$ : peak velocity during late diastole

- Mitral E/A ratio [3]

\section{RESULTS}

Table (1) represents demographic data among studied groups. The results show that both cases of PDA and their controls were matched as regard age in days and sex, and there was no statistical significant difference between them.

The ECHO findings among the studied groups are listed in Table (2). The ECHO findings of both PDA cases and their controls were close to each other and there was no statistical significant difference between them except in size of left atrium which was significantly higher among PDA cases ranged from $0.91 \mathrm{~cm}$ to $1.7 \mathrm{~cm}$ with mean of $1.25 \pm 0.24$, also ratio of LVED $\backslash A O$ was higher among PDA cases than their controls and the difference was statistically highly significant.

Table (3) represents PDA measures among the studied cases. The results show that 9 cases (39\%) of the studied PDA cases presented with high significant PDA, while 14 cases $(61 \%)$ had low significant PDA.

The Difference in ECHO findings among HSPDA and LSPDA are presented in Table (4). The ECHO findings of both types of PDA cases were close to each other and there was no statistical significant difference between them, but the readings were higher in measurements 
among high significant PDA cases than low significant PDA cases.

Statistical analysis

Data were analyzed using IBM SPSS 23.0 for windows (SPSS Inc., Chicago, IL, USA). Quantitative data were expressed as mean \pm

Table (1): Demographic data among studied groups standard deviation (SD). Qualitative data were expressed as frequency and percentage. The ttest, Mann Whitney U test, Chi-square $\left(\mathrm{X}^{2}\right)$ test and Pearson's correlation coefficient (r) test were used when appropriate.

\begin{tabular}{|c|c|c|c|c|c|c|}
\hline Variables & \multicolumn{2}{|c|}{$\begin{array}{l}\text { Cases } \\
\mathbf{N}=\mathbf{2 3}\end{array}$} & \multicolumn{2}{|c|}{$\begin{array}{c}\text { Controls } \\
\mathbf{N}=\mathbf{2 3}\end{array}$} & $\begin{array}{l}\text { Test of } \\
\text { sig. }\end{array}$ & P-value \\
\hline $\begin{array}{c}\text { Agel days } \\
\text { Range }\end{array}$ & \multicolumn{2}{|c|}{$\begin{array}{l}54.9 \pm 39.5 \\
3-150 \text { days }\end{array}$} & \multicolumn{2}{|c|}{$\begin{array}{l}62.7 \pm 57.5 \\
1-165 \text { days }\end{array}$} & $\begin{array}{l}\text { t-test } \\
0.546\end{array}$ & 0.578 \\
\hline $\begin{array}{c}\text { Sex } \\
\text { Male }\end{array}$ & $\mathbf{N}$ & $\%$ & $\mathbf{N}$ & $\%$ & $\mathbf{X}^{2}$ & P-value \\
\hline Female & $\begin{array}{l}12 \\
11\end{array}$ & $\begin{array}{l}52.2 \\
47.8\end{array}$ & $\begin{array}{l}11 \\
12\end{array}$ & $\begin{array}{l}47.8 \\
52.2\end{array}$ & 0.000 & 1.0 \\
\hline
\end{tabular}

Table (2): ECHO findings among the studied groups

\begin{tabular}{|c|c|c|c|c|c|}
\hline \multirow{2}{*}{\multicolumn{2}{|c|}{ Variables }} & $\begin{array}{l}\text { Cases } \\
\mathrm{N}=23\end{array}$ & $\begin{array}{c}\text { Controls } \\
\mathbf{N}=\mathbf{2 3}\end{array}$ & t-test & P-value \\
\hline & & Mean \pm SD & Mean \pm SD & & \\
\hline \multirow[t]{2}{*}{ Systolic functions: } & $\begin{array}{c}\text { EF (\%) } \\
\text { Range }\end{array}$ & $\begin{array}{c}72.9 \pm 9.43 \\
44-94\end{array}$ & $\begin{array}{c}70.4 \pm 5.98 \\
(41-90)\end{array}$ & 1.2 & 0.239 \\
\hline & $\begin{array}{l}\text { FS (\%) } \\
\text { Range }\end{array}$ & $\begin{array}{c}40 \pm 7.93 \\
20-64\end{array}$ & $\begin{array}{c}37.7 \pm 5.27 \\
(20-61)\end{array}$ & 1.17 & 0.248 \\
\hline \multirow[t]{3}{*}{ Diastolic functions: } & $\begin{array}{l}E^{\prime}(\mathbf{m} l s e c) \\
\text { Range }\end{array}$ & $\begin{array}{c}1.005 \pm 0.73 \\
0.37-3.1\end{array}$ & $\begin{array}{l}0.78 \pm 0.21 \\
(0.41-2.5)\end{array}$ & 1.42 & 0.652 \\
\hline & $\begin{array}{l}\mathbf{A}^{\prime}(\mathrm{m} l s e c) \\
\text { Range }\end{array}$ & $\begin{array}{c}0.69 \pm 0.41 \\
0.23-2.1\end{array}$ & $\begin{array}{c}0.61 \pm 0.21 \\
(0.23-2)\end{array}$ & 0.759 & 0.432 \\
\hline & $\begin{array}{c}\text { E\A } \\
\text { Range }\end{array}$ & $\begin{array}{c}1.48 \pm 0.45 \\
0.66-2.7\end{array}$ & $\begin{array}{l}1.43 \pm 0.58 \\
(0.63-2.7)\end{array}$ & 0.376 & 0.709 \\
\hline \multirow{7}{*}{ Measures: } & $\begin{array}{l}\text { LA (cm) } \\
\text { Range }\end{array}$ & $\begin{array}{c}1.25 \pm 0.24 \\
0.91-1.7\end{array}$ & $\begin{array}{l}1.44 \pm 0.36 \\
(0.95-1.4)\end{array}$ & 2.3 & $0.03^{*}$ \\
\hline & $\begin{array}{c}\text { RA (cm) } \\
\text { Range }\end{array}$ & $\begin{array}{c}1.05 \pm 0.17 \\
(0.7-1.4)\end{array}$ & $\begin{array}{c}1.13 \pm 0.28 \\
(0.7-1.5)\end{array}$ & 1.16 & 0.257 \\
\hline & $\begin{array}{c}\text { AO }(\mathbf{c m}) \\
\text { Range }\end{array}$ & $\begin{array}{c}1.2 \pm 0.15 \\
(0.91-1.47)\end{array}$ & $\begin{array}{c}1.28 \pm 0.24 \\
(0.9-1.5)\end{array}$ & 1.3 & 0.2 \\
\hline & $\begin{array}{c}\text { LVED (cm) } \\
\text { Range }\end{array}$ & $\begin{array}{c}1.85 \pm 0.44 \\
(0.7-3.1)\end{array}$ & $\begin{array}{c}1.82 \pm 0.54 \\
(0.5-2.9)\end{array}$ & 0.256 & 0.799 \\
\hline & $\begin{array}{c}\text { LVES (cm) } \\
\text { Range }\end{array}$ & $\begin{array}{l}1.14 \pm 0.35 \\
(0.5-2)\end{array}$ & $\begin{array}{c}1.23 \pm 0.17 \\
(0.5-2)\end{array}$ & 1.26 & 0.216 \\
\hline & $\begin{array}{c}\text { IVS (cm) } \\
\text { Range }\end{array}$ & $\begin{array}{c}0.46 \pm 0.13 \\
(0.2-0.7)\end{array}$ & $\begin{array}{c}0.504 \pm 0.35 \\
(0.2-0.7)\end{array}$ & 0.591 & 0.59 \\
\hline & LVED\AO & $\begin{array}{c}1.88 \pm 0.51 \\
(1.2-3)\end{array}$ & $\begin{array}{l}1.19 \pm 0.46 \\
(0.65-2.7)\end{array}$ & 4.86 & $0.000^{* *}$ \\
\hline
\end{tabular}


Table (3): PDA measures among the studied cases

\begin{tabular}{|c|c|c|c|}
\hline \multirow{2}{*}{\multicolumn{2}{|c|}{ Variables }} & \multicolumn{2}{|c|}{$\begin{array}{l}\text { Cases } \\
\mathrm{N}=\mathbf{2 3}\end{array}$} \\
\hline & & \multicolumn{2}{|c|}{ Mean \pm SD } \\
\hline \multirow{5}{*}{ Measure } & $\begin{array}{c}\text { Diameter } \backslash \mathrm{mm} \\
\text { Range }\end{array}$ & \multicolumn{2}{|c|}{$\begin{array}{c}3.1 \pm 1.68 \\
(1-9)\end{array}$} \\
\hline & $\begin{array}{c}\text { Length Imm } \\
\text { Range }\end{array}$ & \multicolumn{2}{|c|}{$\begin{array}{c}6.45 \pm 4.77 \\
(3-27)\end{array}$} \\
\hline & $\begin{array}{c}\text { Maximum velocity }(\mathrm{mm} \backslash \mathrm{sec}) \\
\text { Range }\end{array}$ & \multicolumn{2}{|c|}{$\begin{array}{c}14.5 \pm 13.18 \\
(1.25-52)\end{array}$} \\
\hline & Types & $\mathbf{N}$ & $\%$ \\
\hline & $\begin{array}{l}\text { High significant PDA } \\
\text { Low significant PDA }\end{array}$ & $\begin{array}{c}9 \\
14\end{array}$ & $\begin{array}{l}39 \\
61\end{array}$ \\
\hline
\end{tabular}

Table (4): Difference in ECHO findings among HSPDA and LSPDA

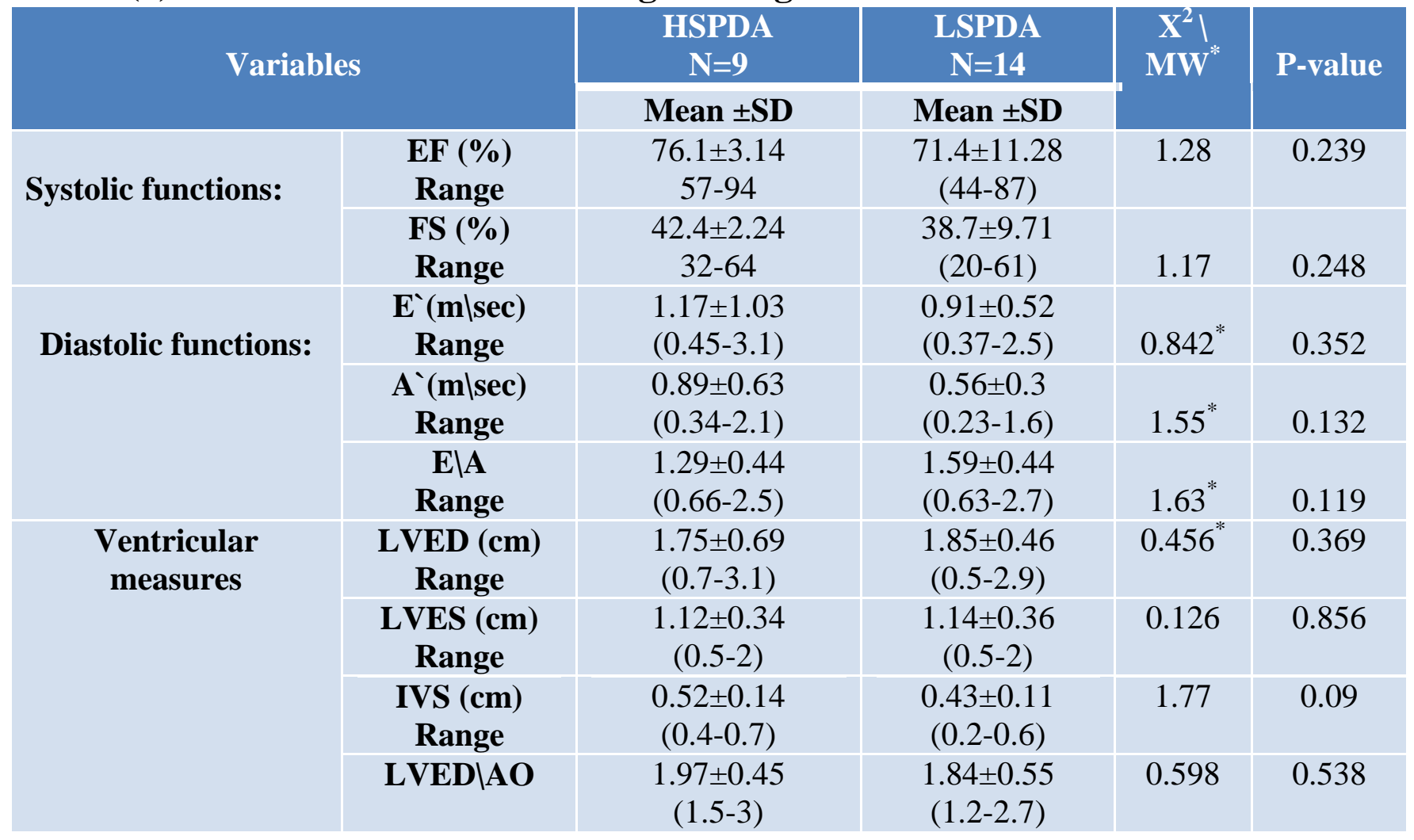




\section{PDA types}

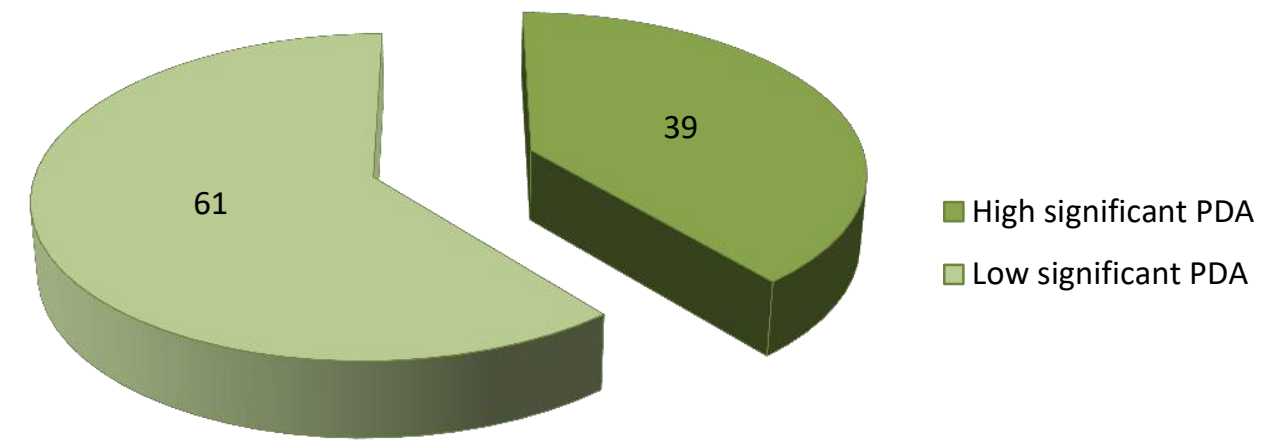

Figure 1: Types of PDA present among studied cases

\section{DISCUSSION}

Patent ductus arteriosus (PDA) is a part of the typical morbidity profile of the preterm infant, with a high incidence of $80-90 \%$ in extremely low birth weight infants born before 26 weeks of gestation. Whereas spontaneous closure of the ductus arteriosus (DA) is likely in term infants, it is less so in preterm ones [4].

Neonatologists often look to echocardiogram to clue if a hemodynamically significant patent ductus arteriosus (HSPDA) is present, coring enough flow to be a threat to a premature infant they are treating [2].

The well-known left atrium to aorta dimension ratio (LA/AO) has been applied for this purpose since the days when M-Mode echocardiography was the only tool available [5].

Regarding age distribution, the age ranged from 3 to 150 days in cases group and from 1 to 165 days in control group. There was no significant difference between both groups [Table 1]. While in [6] study, the mean chronological age was 16.8 days $(0-182)$ For the neonates with PDA, and 21 days (1-126) for the normal group with no significant difference between both groups.

Regarding sex distribution, the incidence of PDA was higher on males (52.2\%) than in females $(47.8 \%)$ with no significant difference. This was in accordance with Bulbul et al., 2015[5] who found no significant difference between males and females.

ECHO findings among the studied group showed the following!

Assessment of the systolic functions using Ejection fraction and Fractional shortening showed a non-significant difference between both case and control. This was groups with pvalue $=0.239$ and 0.248 respectively [Table 2] in agreement both groups.

For the diastolic functions, the Peak early ( $\left.E^{\prime}\right)$ and atrial (A') flow velocities were nonsignificantly different between case and control groups in our study with $\mathrm{p}$ value $=0.652$ for $\mathrm{E}^{\prime}$ and 0.432 for $\mathrm{A}^{\prime}$ [Table 2]. This was in contrast to Schmitz et al., 2004 study [ ] which was done on one group of preterm neonates revealed that peak early (E') and atrial (A') flow velocities were significantly different in same group of VLBW neonates when examined on day $3.8 \pm 1$ and day $14 \pm 2$ after birth comparing the heart measurements before and after PDA closure while our study measured the PDA in one group without follow up compared to healthy infants. 
Our study showed E'/A' between both groups was not significantly different with $\mathrm{p}$-value= 0.709 [Table 2]. This was supported by Khositseth et al., 2011[7] who stated nonsignificant difference in E'/A' between closed and opened PDA groups.

Our study showed significant difference in left atrial size between both groups with $\mathrm{p}$-value = 0.03 [Table 2], which was in agreement with Ognean et al., 2016 who revealed significant difference between both groups with $\mathrm{p}$-value < 0.05 .

As regard right atrial and aorta size, there was non-significant difference between both groups with $\mathrm{p}$-value $=0.257$ and 0.2 respectively [Table 2]. Ognean et al., 2016[8] also revealed no significant difference between both groups with $p$-value $>0.05$.

LVED and LVES were not significantly different between both groups with p-value = 0.799 and 0.216 [Table 2]. Gupta et al., 2011[9] were against our results showing significant difference in closed and opened PDA groups regarding LVED and LVES with p-value < 0.001 one day before and one day after transcatheter closure of PDA in the same group while, we studied two groups including PDA patients and healthy infants without follow up.

LVED $\backslash A O$ was highly significantly difference between both groups in our study with $p$-value= 0.000 [Table 2]. Condò et al., 2012[10] showed also significant difference between both groups supporting our results.

PDA measures among our studied cases were revealed that $39 \%$ of all PDA cases were hemodynamically significant PDA (HSPDA) compared to $61 \%$ of low significant cases (LSPDA) [Table $3 \&$ figure 1].

$\mathrm{ECHO}$ findings among the case group differentiating HSPDA versus LSPDA showed the following:

Assessment of the systolic functions using Ejection fraction and Fractional shortening showed non-significant difference between both case and control groups with p-value $=0.239$ and 0.248 respectively [Table 4]. This was in agreement with Khositseth et al., 2011[7] who also showed non-significant difference between both groups.

For the diastolic functions, the Peak early (E') and atrial (A') flow velocities and $\mathrm{E}^{\prime} \backslash \mathrm{A}^{\prime}$ were non-significantly different between case and control groups in our study [Table 4].

This was supported by Khositseth et al., 2011[7] who stated non-significant difference in $E^{\prime} \backslash A^{\prime}$ between closed and opened PDA groups.

There were no significant differences in other measures between HSPDA and LSPDA regarding LVED, LVES, IVS and LVED/AO. This was in agreement with Sehgal McNamara 2009[2] study which showed no significant differences between HSPDA and LSPDA regarding LVED, LVES, IVS and LVED/AO.

\section{CONCLUSION}

Clinical assessment is somewhat helpful at detecting PDA early in the course of sick infants. Echocardiography is a safe method of detecting PDA and classifying it as HSPDA and LSPDA.

\section{Declaration of interest}

The authors report no conflicts of interest. The authors alone are responsible for the content and writing of the paper.

Funding information: None declared

\section{REFERENCE}

1. Teixeira, L. S., \& McNamara, P. J. Enhanced intensive care for the neonatal ductus arteriosus. Acta Paediatrica 2006; 95(4): 394-403

2. Sehgal, A., \& McNamara, P. J. Does echocardiography facilitate determination of hemodynamic significance attributable to the ductus arteriosus?. European journal of pediatrics, 2009; 168(8): 907-914.

3. Van de Veire, N. R., Marsan, N. A., Schuijf, J. D., Bleeker,G.B.,Wijffels,M.C.,Van Ervan,l.,...\&Bax, J. J. Noninvasive imaging of cardiac venous anatomy with 64-slice multi-slice computed tomography and noninvasive assessment of left ventricular dyssynchrony by 3-dimensional tissue synchronization imaging in patients with heart failure scheduled for cardiac resynchronization therapy. American Journal of Cardiology, 2008; 101(7): 1023-1029

4. Arlettaz, R. echocardiographic evaluation of Patent Ductus Arteriosus in Preterm infants. Frontiers in pediatrics 2017; 5:147. 
5. Clyman, R. I., Couto, J., \& Murphy, G. M. Patent ductus arteriosus: are current neonatal treatment options better or worse than no treatment at all? Seminars in perinatology 2012; 36 (2): 123-129.

6. Jantzen DW, Aldoss O, Sanford B, Fletcher SE, Danford DA, Kutty S. Is Combined Atrial Volumetrics by Two-Dimensional Echocardiography a Suitable Measure for Quantitative Assessment of the Hemodynamic Significance of Patent Ductus Arteriosus in Neonates and Infants? Echocardiography, 2010; 27(6): 696-701.

7. Nuntnarumit $\mathbf{P}$, Chongkongkiat $\mathbf{P}$, Khositseth $\mathbf{A}$. $\mathrm{N}$-terminal-pro-brain natriuretic peptide: a guide for early targeted indomethacin therapy for patent ductus arteriosus in preterm Infants. Acta Paediatrica, 2011; 100(9): 1217-1221.
8. Ognean M L, Boantă O, Kovacs S, Zgarcea C, Dumitra R, Olaire E, Andreicut D. Persistent Ductus Arteriosus in Critically Ill Preterm Infants. The Journal of Critical Care Medicine, 2016; 2(4): 175-184.

9. Gupta SK, Krishnamoorthy KM, Tharakan JA, Sivasankaran S , Sanjay G, Bijulal $s$ et al., Percutaneous closure of patent ductus arteriosus in children: Immediate and short-term changes in left ventricular systolic and diastolic function. Annals of pediatric cardiology 2011; 4(2): 139.

10. Condò M, Evans N, Bellù R, Klockow $\mathbf{M}$. Echocardiographic assessment of ductal significance: retrospective comparison of two methods. Archives of Disease in Childhood-Fetal and Neonatal Edition, 2012; 97(1): F35-F38.

To Cite This Article: Azza AK, Amal MA, Shimaa ME*. Evaluation of Patent Ductus Arteriosus by Using two
Dimensional Echocardiography in Infant and Neonate.ZUMJ 2019;25(6);817-824.DOi:
10.21608/zumj.2019.10786.11220.

